\title{
sciendo
}

\section{THE ASSESSMENT OF THE EFFICACY OF STRS PANELS RECOMMENDED BY THE ISAG FOR CANINE PEDIGREES ANALYSIS FOR FORENSIC CASEWORK}

\author{
Anna Radko ${ }^{1 *}$, Angelika Podbielska ${ }^{1}$, Izabela A. Wierzbowska ${ }^{2}$ \\ ${ }^{1}$ Department of Animal Molecular Biology, National Research Institute of Animal Production, 32-083 Balice n. Kraków, Poland \\ ${ }^{2}$ Faculty of Biology, Institute of Environmental Sciences, Jagiellonian University, \\ Gronostajowa 7, 30-387 Kraków, Poland \\ •Corresponding author: anna.radko@iz.edu.pl
}

\begin{abstract}
Canine DNA is widely used in forensic investigations, particularly in cases of dog attacks on humans. Nowadays, STR markers are employed worldwide in forensic laboratories to test human and animal genotypes. In the study we analysed the effectiveness of $18 \mathrm{STR}$ panel as previously recommended by ISAG and the same panel with three additional markers - 21 STR, which has been recommended by ISAG as the core panel for dog identification since 2016. We calculated the PD, $P_{I D}$ for these sets of panels and estimated RMP based on the DNA profile obtained during an investigation of a woman bitten by a dog. The high combined CPD value for 18 and 21 STRs showed values close to 1.0. The $\mathrm{CP}_{\mathrm{ID}}$ value for theses panels was $5.2 \times 10^{-10}$ to $6.4 \times 10^{-14}$. Statistical analysis estimated the random $\mathrm{DNA}$ match, in the case of the woman bitten by a dog, with a probability of $4.3 \times 10^{19}$ and $2.8 \times 10^{22}$, using 18 and 21 STR panels respectively, and that the canine DNA profile from the crime scene originated from the suspected dog and not from another random dog. Our results show that both STR panels can be used effectively for individual identification and forensic casework.
\end{abstract}

Key words: forensic science, DNA profiling, domestic dog, RMP

DNA analysis of microsatellite markers (STR, short tandem repeat) is commonly used for identification, parentage and kinship testing in animals. Nowadays, it is among the most objective and reliable methods used in criminal and civil forensic genetic cases (Eichmann et al., 2006; Halverson and Basten, 2005; Kanthaswamy et al., 2009; Berger et al., 2014). Studies of animal DNA have been used in canine identification in court cases. For example, they are used in cases of animals theft, poaching, cruelty to animals but also in criminal investigations involving humans, in particular in cases of identification of dogs that attack humans (Tsuji et al., 2008; Clarke and Vandenberg, 2010; Ciampolini et al., 2017; Drumright et al., 2020). Dog bite-related injuries remain a serious public health and safety concern on a worldwide scale. For example, in just the USA 4.5-4.7 million people are bitten annually (Clarke and Vandenberg, 2010). It is important to provide accurate evidence based on canine biological samples. Biological samples, in the form of hair samples, blood and saliva traces, left behind at the crime scene, can be used for DNA profiling and become an effective tool in forensic investigations (Eichmann et al., 2006; Kanthaswamy et al., 2009; Clarke and Vandenberg, 2010). The successful settlement of the case depends on secured biological evidence, DNA analysis but also statistical analysis. During the forensic investigation, the obtained DNA profiles of known reference sample and of the crime scene evidence are identical, it is consequently assumed that they belong to the same individual, but never with $100 \%$ certainty. That is why determination of criminal investigations using DNA evidence is subject to some uncertainty. The use of statistical methods allows for the quantification of this uncertainty and presents the quantitative value of the evidence. DNA profiling is based on a calculus of probability. Thus, during the process of providing an expert opinion for court, in order to assess the power of proof, it is necessary to estimate the probability of the DNA profiles match. For this calculation a random match probability - RMP is used, which shows frequency of observed DNA profile based on actual population data (Koehler et al., 1995; Forrester et al., 2018; Giacalone et al., 2018; Kanthaswamy et al., 2019). The value of RMP and the use of the kit for forensic investigations greatly depends on the number of used STR markers (DeNise et al., 2004). Currently, the International Society for Animal Genetics (ISAG) recommends an extension of the core panel 18 STR, until now used for canine identification and parentage testing, to include three additional markers. The use of additional markers increases costs of the analysis. With current pressure laid on laboratories to drive down costs, it requires an estimation of the effectiveness of the extended STR set for the 
identification analysis. In our study we aimed to compare the efficacy of two panels, i.e. set 18 STR and extended 21 STR with the three additional markers, used for identification of dogs and forensic investigations. To compare the STR panels we calculated power of discrimination - PD and probability of identity - $\mathrm{P}_{\text {ID }}$ (Kimberly, 1998; Waits et al., 2001). Additionally, RMP was assessed based on 18 STR and 21 STR panels during DNA profiling of the biological evidence samples obtained from a victim - woman bitten by a dog.

\section{Material and methods}

To calculate cumulated $\mathrm{PD}$ and $\mathrm{P}_{\mathrm{ID}}$, for all markers, two dog breeds were selected: a German Shepherd (GS) and an Irish Wolfhound (IW), respectively the most and the least numerous dog breeds in Poland. The buccal swabs or blood samples for analysis were collected from 190 individuals of GS and 91 from IW, respectively.

The RMP was determined using the DNA profile obtained, from a case of a dog attack on a woman as requested by the police. The incident took place in the city park where several dogs were present with a few individuals that were GS. The dogs were ranging without confinement. Based on the description of the victim, two dogs were suspected. The evidence samples were secured from the victim after the dog attack and from the two suspected dogs. Evidence sample 1 contained traces collected by sterile swabs from the victims' trousers, with evident stains which could have been made by a dog. The woman who was bitten indicated a dog whose owner denied the incident and indicated another dog instead. The blood samples were collected from both suspected dogs which made reference samples 1 and 2. To estimate RMP, for the identical DNA profile obtained from the evidence and reference samples, we used a canine database which consists of 845 dog individuals collected from different breeds (such as GS, Yorkshire Terrier, Maltese, Golden Retriever, Labrador, French Bulldog, IW). The database is a property of the National Research Institute of Animal Production.

In the analysis $21 \mathrm{STR}$ and Amel locus were used, recommended by ISAG as the core panel for identification of individuals and parentage testing in dogs. The following microsatellite markers were used: AHTk211, CXX279, REN169O18, INU055, REN54P11, INRA21, AHT137, REN169D01, AHTh260, AHTk253, INU005, INU030, FH2848, AHT121, FH2054, REN162C04, AHTh171, REN247M23, and three additional markers: AHTH130, REN105L03, REN64E19, currently recommended for dogs identification (https://www.isag.us/ Docs/AppGenCompAnim2019.pdf). Amel locus was excluded from the statistical analysis.

DNA was extracted from swabs and blood using the Sherlock AX Kit (A\&A Biotechnology, Gdynia, Poland), following the manufacturer's protocol. The extracts were quantified with a NanoDrop 2000 spectrophotometer
(Thermo Fisher Scientific, Wilmington, DE, USA). The STR loci were amplified using Phusion U Hot Start DNA Polymerase (Thermo Fisher Scientific) and the PCR reaction was performed using a Veriti ${ }^{\circledR}$ Thermal Cycler amplifier (Applied BioSystems, Foster City, CA, USA), using the following thermal profile: $5 \mathrm{~min}$. of initial DNA denaturation at $98^{\circ} \mathrm{C}$, followed by 30 cycles of denaturation at $98^{\circ} \mathrm{C}$ for $15 \mathrm{~s}$, annealing at $58^{\circ} \mathrm{C}$ for $75 \mathrm{~s}$, elongation of starters at $72^{\circ} \mathrm{C}$ for $30 \mathrm{~s}$ and final elongation of starters at $72^{\circ} \mathrm{C}$ for $5 \mathrm{~min}$.

Analysis of the obtained PCR products was performed using the ABI 3130xl Genetic Analyzer (Applied Biosystems, Foster City, CA). The amplified DNA fragments were subjected to electrophoresis in $7 \%$ denaturing POP-7 polyacrylamide gel in the presence of a standard length of $500 \mathrm{Liz}$ and a reference sample. The results of the electrophoretic separation were analysed automatically using the GeneMapper ${ }^{\circledR}$ Software 4.0 (Applied Biosystems, Foster City, CA, USA). The methods used in the laboratory met requirements on the ISO/IEC 17025:2017 and were confirmed in the Comparison Test organized by ISAG (ISAG Lab code: 84451).

\section{Data analysis}

The Hardy-Weinberg equilibrium (HWE) of the 21 STR loci was tested by exact test using an algorithm based on Markov Chain Monte Carlo methods (Guo and Thompson, 1992). The inbreeding coefficient $-\mathrm{F}_{\text {is }}$ was estimated by the Wright F statistic method (Wright, 1978). Genetic parameters, i.e. PD (Kimberly, 1998), PID (Waits et al., 2001) were computed by the formulas:

$$
\begin{gathered}
C P D=1-\prod_{i=1}^{n}\left(1-P_{I D}\right) \\
P_{I D}=\sum p_{i}^{4}+\sum \sum\left(2 p_{i} p_{j}\right)^{2} \quad C P_{I D}=\prod P_{I D}
\end{gathered}
$$

where:

$p_{j k}$ - allele frequency $j, k$ for $i$-locus, $p_{i} p_{, j}-$ allele frequency $j, i$,

$C P D$ - cumulative power of discrimination,

$C P_{I D}$ - cumulative probability of identity.

The combined random match probabilities RMP were calculated using allele frequencies (Koehler et al., 1995). The statistical analysis was carried out by the IMGSTAT software (ver. 2.10.1, 2009), which supports the laboratory of the National Research Institute of Animal Production.

\section{Results}

Data for all microsatellite loci were consistent with the HWE equilibrium, except for three markers, for 
which the difference between the frequency of observed and expected genotypes in these loci was significant at the 5\% level. The markers INRA21, REN162c04 and REN169D01 in IW dog breed showed deviation from equilibrium (Table 1). Among these markers for the IW dog breed, coefficients of inbreeding $\mathrm{F}_{\text {is }}$ were checked and only in REN162C04 locus we observed the increase of heterozygosity $\left(\mathrm{F}_{\text {is }}=0.108\right)$. The calculated value of per-marker inbreeding coefficient $\mathrm{F}_{\text {is }}$ ranged from -0.127 to 0.128 (Table 1).

Table 1. Hardy-Weinberg equilibrium and coefficient of inbreeding $F_{\text {is }}$ for 21 microsatellites in two dog breeds German Shepherd (GS) and Irish Wolfhound (IW)

\begin{tabular}{|c|c|c|c|c|c|}
\hline \multicolumn{3}{|c|}{ GS $(n=190)$} & \multirow{2}{*}{\multicolumn{2}{|c|}{$\frac{\text { IW }(n=91)}{\text { HWE }}$}} & \multirow[b]{3}{*}{ Fis } \\
\hline \multirow{2}{*}{ Locus } & \multicolumn{2}{|c|}{ HWE } & & & \\
\hline & $\mathrm{P}$-value & SE & P-value & SE & \\
\hline AHT121 & 0.250 & 0.084 & 0.084 & 0.033 & -0.056 \\
\hline AHT137 & 0.516 & 0.091 & 0.084 & 0.033 & -0.096 \\
\hline АНTH171 & 0.491 & 0.040 & 0.458 & 0.036 & -0.100 \\
\hline АНТН 260 & 0.089 & 0.014 & 0.238 & 0.021 & -0.019 \\
\hline AHTK211 & 0.073 & 0.011 & 0.947 & 0.004 & -0.022 \\
\hline AHTK253 & 0.491 & 0.040 & 0.927 & 0.006 & 0.023 \\
\hline CXX279 & 0.624 & 0.045 & 0.166 & 0.032 & -0.018 \\
\hline FH2054 & 0.918 & 0.021 & 0.057 & 0.023 & 0.128 \\
\hline FH2848 & 0.083 & 0.041 & 0.507 & 0.010 & 0.004 \\
\hline INRA21 & 0.062 & 0.040 & $0.045^{*}$ & 0.024 & -0.098 \\
\hline INU005 & 0.594 & 0.053 & 0.358 & 0.008 & -0.041 \\
\hline INU030 & 0.084 & 0.015 & 0.358 & 0.008 & -0.001 \\
\hline INU055 & 0.947 & 0.017 & 0.097 & 0.122 & 0.104 \\
\hline REN162C04 & 0.066 & 0.021 & $0.037 *$ & 0.001 & -0.108 \\
\hline REN169D01 & 0.066 & 0.021 & $0.037^{*}$ & 0.001 & -0.058 \\
\hline REN169018 & 0.072 & 0.029 & 0.899 & 0.012 & -0.090 \\
\hline REN247M23 & 0.244 & 0.032 & 0.138 & 0.021 & 0.118 \\
\hline REN54P11 & 0.357 & 0.025 & 0.679 & 0.015 & -0.051 \\
\hline AHTH130 & 0.546 & 0.034 & 0.679 & 0.015 & -0.096 \\
\hline REN105L03 & 0.093 & 0.018 & 0.726 & 0.015 & -0.103 \\
\hline REN64E19 & 0.513 & 0.075 & 0.081 & 0.020 & -0.127 \\
\hline Mean value & & & & & -0.03 \\
\hline
\end{tabular}

HWE $=$ Hardy-Weinberg equilibrium; $\mathrm{F}_{\mathrm{is}}=$ inbreeding coefficient $\mathrm{SE}=$ standard error, $\mathrm{n}=$ number of individuals, $* \mathrm{P}<0.05$.

The power of discrimination for the whole set of 18 STR and for set containing 3 additional markers showed high values close to 1.0 . The probability of identity for combination of 18 STR loci examined in this study was $\mathrm{CP}_{\text {ID }}=5.8 \times 10^{-12}$ and $\mathrm{CP}_{\text {ID }}=5.2 \times 10^{-10}$ for GS and IW dog breed respectively, while the $\mathrm{P}_{\mathrm{ID}}$ for all $21 \mathrm{STR}$ was $\mathrm{CP}_{\mathrm{ID}}=6.4 \times 10^{-14}$ and $\mathrm{CP}_{\mathrm{ID}}=6.8 \times 10^{-11}$ for the same breeds (Table 2 ).
Table 2. Power of discrimination and probability of identity for 21 microsatellites in two dog breeds German Shepherd (GS) and Irish Wolfhound (IW)

\begin{tabular}{l|c|c|c|c}
\hline \multirow{2}{*}{ Locus } & \multicolumn{2}{c|}{$\mathrm{PD}$} & \multicolumn{2}{c}{$\mathrm{P}_{\mathrm{ID}}$} \\
\cline { 2 - 5 } & $\mathrm{GS}$ & $\mathrm{IW}$ & $\mathrm{GS}$ & $\mathrm{IW}$ \\
$(\mathrm{n}=190)$ & $(\mathrm{n}=91)$ & $(\mathrm{n}=190)$ & $(\mathrm{n}=91)$ \\
\hline AHT121 & 0.650 & 0.828 & 0.348 & 0.159 \\
AHT137 & 0.656 & 0.290 & 0.353 & 0.718 \\
AHTH171 & 0.820 & 0.790 & 0.180 & 0.218 \\
AHTH260 & 0.827 & 0.524 & 0.164 & 0.468 \\
AHTK211 & 0.809 & 0.647 & 0.182 & 0.352 \\
AHTK253 & 0.540 & 0.662 & 0.461 & 0.335 \\
CXX279 & 0.786 & 0.737 & 0.201 & 0.261 \\
FH2054 & 0.847 & 0.775 & 0.150 & 0.241 \\
FH2848 & 0.702 & 0.686 & 0.300 & 0.317 \\
INRA21 & 0.838 & 0.812 & 0.162 & 0.179 \\
INU005 & 0.735 & 0.732 & 0.271 & 0.265 \\
INU030 & 0.710 & 0.573 & 0.303 & 0.427 \\
INU055 & 0.838 & 0.581 & 0.168 & 0.392 \\
REN162C04 & 0.805 & 0.574 & 0.194 & 0.323 \\
REN169D01 & 0.607 & 0.206 & 0.395 & 0.808 \\
REN169O18 & 0.905 & 0.724 & 0.091 & 0.276 \\
REN247M23 & 0.506 & 0.684 & 0.493 & 0.295 \\
REN54P11 & 0.724 & 0.655 & 0.274 & 0.338 \\
AHTH130 & 0.890 & 0.290 & 0.109 & 0.718 \\
REN105L03 & 0.829 & 0.715 & 0.165 & 0.263 \\
REN64E19 & 0.374 & 0.742 & 0.619 & 0.231 \\
18-STR & 0.99999999999 & 0.99999999890 & $5.80 \mathrm{E}^{-12}$ & $5.19 \mathrm{E}^{-10}$ \\
21-STR & 1.0000000000 & 0.99999999987 & $6.43 \mathrm{E}^{-14}$ & $6.83 \mathrm{E}^{-11}$ \\
\hline
\end{tabular}

Table 3. The alleles obtained at 21 STR loci from the crime scene sample and from the two suspect dogs

\begin{tabular}{|c|c|c|c|}
\hline \multirow[b]{2}{*}{ Locus } & \multicolumn{3}{|c|}{ Allele designations in base pair } \\
\hline & $\begin{array}{l}\text { crime scene } \\
\text { sample from } \\
\text { the victim }\end{array}$ & $\begin{array}{l}\text { reference sample } \\
\text { from the suspected } \\
\text { dog } 1\end{array}$ & $\begin{array}{l}\text { reference sample } \\
\text { from the suspected } \\
\operatorname{dog} 2\end{array}$ \\
\hline AHT121 & $102 / 104$ & $102 / 104$ & $80 / 102$ \\
\hline AHT137 & $137 /$ & $137 /$ & $131 /$ \\
\hline АНTH171 & $219 / 223$ & $219 / 223$ & $233 /$ \\
\hline АНTH260 & $238 /$ & $238 /$ & $242 / 252$ \\
\hline AHTK211 & $89 / 91$ & $89 / 91$ & $89 /$ \\
\hline AHTK253 & $288 /$ & $288 /$ & $288 /$ \\
\hline CXX279 & $116 /$ & $116 /$ & $116 /$ \\
\hline FH2054 & $168 / 172$ & $168 / 172$ & $160 /$ \\
\hline FH2848 & $240 /$ & $240 /$ & $240 / 242$ \\
\hline INRA21 & $91 / 95$ & $91 / 95$ & $99 /$ \\
\hline INU005 & $126 /$ & $126 /$ & $126 /$ \\
\hline INU030 & $144 / 150$ & $144 / 150$ & $150 /$ \\
\hline INU055 & $214 / 218$ & $214 / 218$ & $210 / 220$ \\
\hline REN162C04 & $206 /$ & $206 /$ & $206 / 212$ \\
\hline REN169D01 & $216 /$ & $216 /$ & $212 / 216$ \\
\hline REN169018 & $158 / 168$ & $158 / 168$ & $168 /$ \\
\hline REN247M23 & $270 /$ & $270 /$ & $268 / 278$ \\
\hline REN54P11 & $226 /$ & $226 /$ & $232 / 238$ \\
\hline АНТН130 & $129 / 131$ & $129 / 131$ & $127 / 131$ \\
\hline REN105L03 & $227 /$ & $227 /$ & $231 / 233$ \\
\hline REN64E19 & $155 /$ & $155 /$ & $153 / 155$ \\
\hline
\end{tabular}


During the evaluation of the forensic case study of the dog attack, the full genetic profiles were obtained based on the analysis of the evidence and reference samples. Obtained DNA profiles were used for DNA profiles comparative analysis (Table 3 ).

DNA profile for the evidence material did not match canine DNA profile obtained from the reference dog sample 2. The match was observed only for AHTK253, CXX279, and INU005 loci, for all other markers the genotypes were different. Thus, the suspected dog 2 was excluded as a contributor to the evidence samples on the victim. However, the evidence sample DNA profile obtained from the victim fully matched with the canine DNA profile from suspect dog reference 1. The identical profile obtained from a blood sample collected on the trousers of the victim and the blood from the suspected dog indicated that this dog might have been involved in the incident (Table 3). Statistical analysis estimated that RMP for 21 STR panel was lower than for 18 STR panel $\left(3.5 \times 10^{-23}\right.$ and $2.3 \times 10^{-20}$ respectively).

\section{Discussion}

Dogs are among the most popular human companion animals. Due to the fact that dogs are in large numbers and many are in close relationships with humans, dogs provide biological evidence for numerous forensic investigations (Eichmann et al., 2006; Kanthaswamy et al., 2009; Clarke and Vandenberg, 2010). The canine genotype STR panel kit recommended by ISAG for the identification of and parentage verification in domestic dogs initially included 18 STR and the Amel gene. Currently the core panel with 21 STR markers is used with three additional markers (AHTH130, REN105L03, REN64E19) added to 18 STR panel. The use of an extended panel often does not allow for the amplification of all markers in one PCR reaction and one electrophoretic separation which, in consequence, increases time and expense of the analyses. It is essential to avoid excess costs and to use the most efficient laboratory tool.

In our study, the mean inbreeding coefficient $\mathrm{F}_{\text {is }}$ was -0.03 and it was similar to a Czech Dachshund, Uruguayan Cimarron, Tatra Shepherd Dog and a Polish Hunting Dog (Přibáňová et al., 2009; Gagliardi et al., 2011; Radko et al., 2018; Goleman et al., 2019). The $\mathrm{F}_{\text {is }}$ results allowed us to exclude increased homozygosity in IW breed. The main reasons for the deviation from HWE in IW breed may be caused by the limited sample size, or non-random mating of purebred dogs (Table 1). For this reason, all markers were used in the further statistical analysis. To compare the efficiency of 18 STR and 21 STR panels genetic parameters based on a standard statistical formula were calculated. We estimated PD and $\mathrm{P}_{\text {ID }}$ for each locus and for all loci together. The power of discrimination is characterised by the probability that two unrelated and randomly selected individuals can be genetically differentiated by the analysis of a marker or a set of markers. The PD for the panel of 16 microsatellite markers (excluding INU005 and AHTk253) for Shiba Inu breed was more than 0.999999 (Arata et al., 2016), while cumulative PD for the 18 and 21 markers in our study was 0.99999999890 and 0.99999999987 , for IW and 0.99999999999 and $\approx 1.0$ for GS, respectively. Both panels showed high values of PD coefficient and can be safely used for identification and kinship testing purposes. Probability of identity was calculated to assess the suitability of tested panels for individual identification. $\mathrm{P}_{\mathrm{ID}}$ shows the probability with which two unrelated, randomly selected individuals in the population will have the same genotype. It is accepted that $\mathrm{CP}_{\mathrm{ID}}$ ranging between $10^{-3}$ and $10^{-4}$ values is sufficiently low for the identification of individuals in natural animal populations (Waits et al., 2001), whereas $\mathrm{CP}_{\mathrm{ID}}$ value estimated only for 15 STR markers in canine amounted to $10^{-8}$ (Eichmann et al., 2006). In our study, $\mathrm{CP}_{\mathrm{ID}}$ ranged between $10^{-10}$ (for IW) and $10^{-14}$ (for GS) for 18 STR and 21 STR panels, respectively. For both breeds the obtained low $\mathrm{CP}_{\mathrm{ID}}$ values should be sufficient to distinguish individual dogs.

In Poland the presence of canine biological evidence is often associated with dog attacks. Poland has about 7.5 million dogs which makes it the second highest dog population in Europe following Great Britain (Duffy et al., 2008). In Poland no study has evaluated the statistics on dog bites. The preliminary reports of the District Veterinary Inspectorate (2009-2012) show that each year the number of dogs placed under epizootic control after a biting incident is growing. In our study we presented results of the forensic case study of a woman who was bitten by a dog. In this case, the DNA match between a suspect dog and genetic material from the crime scene was estimated by the random match probability. The RMP identifies frequency of the studied DNA profile in a reference population. As the RMP gets lower, the probative value of the match gets higher. The probability that the DNA in a random sample from the population has the same specific profile as the DNA in the evidence sample was calculated with RMP coefficient and helped to compare both 18 STR and 21 STR panels. The value of RMP calculated in forensic investigation is strictly attributed to the force of DNA evidence. In our study the RMP for the above mentioned case was obtained based on the DNA profiles of 845 dogs of different breeds. The calculated RMP was $2.3 \times 10^{-20}$ and $3.5 \times 10^{-23}$ for 18 STR and 21 STR panels respectively. The RMP value for 18 STR panel was close to the results for the same STR panel obtained by Kanthaswamy et al. (2009) with RMP $=1.25 \times 10^{-21}$. In our study low RMP values obtained both for 18 and 21 STRs, indicate that it was at least a sextillion times more likely that the reference material belonged to a suspected dog 1 compared to another random dog. The previous studies assessing the efficacy of 10 STR and 17 STR panels showed a slight decrease of RMP, $3.6 \times$ $10^{-5}$ to $3.2 \times 10^{-8}$ respectively (DeNise et al., 2004). It can be deduced that the inclusion of additional three to five STR markers only slightly decreases the value of RMP. 
The obtained low probability of random match of DNA profiles for 18 STR and 21 STR indicates that both panels, as recommended by ISAG panels give almost $100 \%$ accuracy. It also indicates that the DNA profiles belong to the same suspected dog. Therefore, it can be anticipated that these STR panels will be useful for identification testing for most forensic and kinship analyses.

\section{Conclusions}

To conclude, in the present study we examined the genetics parameters - power of discrimination (PD) and probability of identity $\left(\mathrm{P}_{\mathrm{ID}}\right)$ on the basis of genotypes of 21 STRs in German Shepherd (GS) and Irish Wolfhound breeds. Moreover, to estimate the random match probability (RMP), for the identical DNA profile obtained from the evidence samples and the dog suspected of attack on women, we used a canine database with 845 different dog breeds. The low RMP obtained for 21 STR panel was three orders of magnitude lower than for 18 STR panel. The results show that both 18 STR and 21 STR panels can be used effectively for individual identification and forensic casework.

\section{Acknowledgments}

We thank Joanna Peplińska from the British International School of Cracow for English proofreading.

\section{Conflicts of Interest}

The authors declare that they have no conflict of interest.

\section{References}

Arata S., Asahi A., Takeuchi Y., Mori Y. (2016). Microsatellite loci analysis for individual identification in Shiba Inu. J. Vet. Med. Sci., 78: 439-444.

Berger B., Berger C., Hecht W., Hellmann A., Rohleder U., Schleenbecker U., Parson W. (2014). Validation of two canine STR multiplex-assays following the ISFG recommendations for non-human DNA analysis. Forensic. Sci. Int. Genet, 8: 90-100.

Ciampolini R., Cecchi F., Spinetti I., Rocchi A., Biscarini F. (2017) The use of genetic markers to estimate relationships between dogs in the course of criminal investigations. BMC Res. Notes, 10: 414

Clarke M., Vandenberg N. (2010). Dog attack: the application of canine DNA profiling in forensic casework. Forensic Sci. Med. Pathol., 6: 151-157.

DeNise S., Johnston E., Halverson J., Marshall K., Rosenfeld D., McKenna S., Sharp T., Eichmann C., Berger B., Parson W. (2004). A proposed nomenclature for 15 canine-specific polymorphic STR loci for forensic purposes. Int. J. Legal Med., 118: 249-266.

Drumright B., Borg B., Rozzelle A., Donoghue L., Shanti C. (2020).
Pediatric dog bite outcomes: infections and scars. Trauma Surg. Acute Care Open, 5:e000445.

Duffy D.L., Hsu Y., Serpell J.A. (2008). Breed differences in canine aggression. Appl. Anim. Behav. Sci., 114: 441-460.

Eichmann C., Berge B., Parson W. (2006). Relevant aspects for forensic STR analysis of canine DNA: repeat-based nomenclature and sensitive PCR multiplexes. International Congress Series, Elsevier, 1288: 813-815.

Forrester J. A., Weiser T. G., Forrester J. D. (2018). An update on fatalities due to venomous and nonvenomous animals in the United States (2008-2015). Wilderness Environ. Med., 29: 36-44.

Gagliardi R., Llambí S., Garcia C., Arruga M.V. (2011). Microsatellite characterization of Cimarron Uruguayo dogs. Genet. Mol. Biol., 34: $165-168$.

Giacalone M., Giannuzzi M.R., Panarello D. (2018). DNA test to assess criminal responsibility: a Bayesian approach. Qual. Quant., 52: 2837-2853.

Goleman M., Balicki I., Radko A., Jakubczak A., Fornal A. (2019). Genetic diversity of the Polish Hunting Dog population based on pedigree analyses and molecular studies. Livest. Sci., 229: 114-117.

Guo S., Thompson E.A. (1992). Performing the exact test of Hardy-Weinberg proportion for multiple alleles. Biometrics, 48: 361-372.

Halverson J.L., Basten C. (2005). Forensic DNA identification of animal-derived trace evidence: tools for linking victims and suspects. Croat. Med. J., 46: 598-605.

Kanthaswamy S., Tom B.K., Mattila A.M., Johnston E., Dayton M., Kinaga J., Erickson B.J., Halverson J., Fantin D., DeNise S., Kou A., Malladi V., Satkoski J., Budowle B., Smith D.G., Koskinen M.T. (2009). Canine population data generated from a multiplex STR kit for use in forensic casework. J. Forensic Sci., 54: 829-840.

Kanthaswamy S., Oldt R.F., Montes M., Falak A. (2019). Comparing two commercial domestic dog (Canis familiaris) STR genotyping kits for forensic identity calculations in a mixed-breed dog population sample. Anim. Gen., 50: 105-111.

Kimberly A.H. (1998). Statistical analysis of STR data. Promega Corporation Profiles in DNA, 3: 14-15.

Koehler J.J., Chia A., Lindsey S. (1995). The random match probability (RMP) in DNA evidence: irrelevant and prejudicial? Jurimetrics J., 35: 201.

Přibáňová M., Horák P., Schröffelová D., Urban T., Bechyňová R., Musilová L. (2009). Analysis of genetic variability in the Czech Dachshund population using microsatellite markers. J. Anim. Breed. Genet., 126: 311-318.

Radko A., Rubiś D., Szumiec A. (2018). Analysis of microsatellite DNA polymorphism in the Tatra Shepherd Dog. J. App. Anim. Res., 46: 254-256.

Tsuji A., Ishiko A., Kimura H., Nurimoto M., Kudo K., Ikeda N. (2008). Unusual death of a baby: a dog attack and confirmation using human and canine STRs. Int. J. Legal Med., 122: 59-62.

Waits L.P., Luikart G., Taberlet P. (2001). Estimating the probability of identity among genotypes in natural populations: Cautions and guidelines. Mol. Ecol., 10: 249-256.

Wright S. (1978). Evolution and the genetics of populations, variability within and among natural populations. University of Chicago Press, Chicago, USA, Vol. 4.

Received: 23 II 2021

Accepted: 12 X 2021 